\title{
文化漫游与精神家园 当代中国文化散文的公共语境
}

\author{
郑怡
}

The essay explores the public social dimension of the "great cultural essays" as a popular post-socialist genre. It looks into the genre’s emergence and popularity as part of the making of a middleclass taste in contemporary China and its claim to a re-imagined cultural national inheritance. In particular, the discussion focuses on the example of essayist Yu Qiuyu and examines the implications of his successful transformation of an obsolete historical "Culture” into a desirable commodity that offers spiritual home to the aspiring and successful of a “Greater China”.

《月冷繁华》 ${ }^{1}$ 是当代世界出版社文化大散文系中的一集。书的封面上用烫金字选 列出集子的要目, 同时也是对书目的提示, 如 “繁华如梦堪惊” 是作者 “在圆明园 废墟上的启示”。书的封底也非常优雅地用红黑二色勾勒出本书销售策划的要

旨: “品质是一种内在, 品味是一种格调, 品读是一种感觉。” 这个有点老套的书 名和 “三品” 所代表的出版商的销售策略转换成的对读者的诱导, 是文化散文作为 一种后社会主义时期新兴文类的文化审美内涵、题旨及历史承传的隐喻。“月冷” 和 “繁华” 分别提示了谁在抒情感怀以及过去和现在在此文类中的定位。另外它也 在无意间彰显出时尚阶级情趣与 “国族” 文化历史一一后者作为前者理所当然的精 神家园一的关系。

由余秋雨为始作俑者的文化散文如今已被看作最典型的中国新中产读物, 因为它们 几乎囊括了中产情调所必需的题材及文化特征: 旅游, 怀旧, 煽情的文化感怀及感 伤, 等等。 2 《月冷繁华》封底关于此类书籍的自我定位和对读者的要求, 也证实 了这一点：对品位格调的追求、对品质的向往和想象拥有, 确实已成为或被规定或 “自发” 的新中产情结。而这些品位格调的不容质疑的历史文化承传一它们的语境 和来源, 又正是众多文化散文的主流情感结构和内容。因此要讨论文化散文的阶级

1 冯政: 《月冷繁华》, 北京: 当代世界出版社, 2005 年版。

2 周晓虹: 《中国中产解层 调查》, 北京: 社会科学文献出版社, 2005 年版, 第 921 页。 
情趣和文化历史承传，应该从余氏散文开始。 ${ }^{3}$ 不过把余秋雨及其散文作为新兴的 中产情趣的代表有点本末倒置。余作为一个真正的后社会主义时期自助成功的公众 文化人物, 其实是新兴或者更确切地说复兴的中国阶级文化趣味的重造者而不是执 行者。余和他的文化大散文常被看作一种文化现象, 而且是一种少有的既能煽动

“精英” 批评的激情又能引发通俗消费的热狂的文化现象。紧随着余氏现象令人吃 惊的成功而引发的狂热余评在此意义上与余的文化文类实践一样具有启发性。作为 一种新的文化工业现象, 两者都反映并代表了在后社会主义经济社会变革中 “文 化” 作为一种社会审美差异性符号的被重塑改写, 并且凸显了所谓文化精英在这种 常常被模糊地称为文化商业化的过程中所起的作用以及所向往的角色转变。本文拟 从余氏开始的文化散文写作行为中对当代差异性文化品位的塑造及其与 “过去” 国 族精神家园的改写利用, 来探寻文化大散文作为一种文化现象, 无论是 “月冷繁 华” 式的感怀或者是对 “文化苦旅” 的浓墨重染, 所追求并获得极大商业成功的到 底是什么。

余秋雨的《文化苦旅》、《山中笔记》和《文明的碎片》以及后来涌现的众多文化 大散文, 实际上不过是抒情性游记随笔的翻版。一个 “大” 字突出了它们的理直气 壮和浓笔重彩。抒情感怀的游记类文字在九十年代以后的中国大陆以及两岸三地的 华语区的重新走红也许确实应归结于它顺应了某种新中产情趣及生活方式一一方兴 未艾的旅游热、城市怀旧热似乎证实了这一点。但是, “中国新中产” 无论是作为 当代中国的社会经济或历史文化范畴, 都不是既存社会结构性改变结果的代称, 即 它并不是对现成社会现象的形容, 而是一种后社会主义时代社会文化阐释学式的公 共想象，一种新的集国家利益、商品经济、各种不同新旧利益集团及个人之大成而 又在其中各述所需的正在形成的公共话语。因此, 余式 “文化苦旅” 及 “文明的碎 片” 似的文化散文, 与其说是中国新中产的代表读物, 还不如说是这种新中产文化 及审美情趣结构塑造的先锋。本文拟通过对余评及余式散文中文化英雄主义的定位 的重审评议来对此加以讨论。另外还将通过此文类的文史承传及其改写来讨论文化 散文作为这种新公共话语的先锋与 “过去” 和 “现在” 的国族精神家园的关系。

\section{1. 余评及余氏 “文化主义” 的启示}

如前所述, 紧随着余氏现象让人吃惊的成功而来的狂热余评在此意义上与余的文 化、文学实践一样具有启发性。作为一种同样的新的文化工业现象, 两者都反映并 代表了在后社会主义经济, 社会变革中 “文化” 作为一种差异性的社会审美符号的 重塑改写, 并且凸现了所谓文化精英在这种商业化新主流公共话语的建设中所起的 作用及所向往的角色转变。

\footnotetext{
${ }^{3}$ 甚至可以说余氏散文成功后涌现的大量 “文化大散文” 或多或少地都是对余氏行为及范式的模 仿。
}

PORTAL Vol. 4, No.1, January 2007 
李书否在他的 “余秋雨评点” 一文中非常准确地指出了余评的症结所在, 即它们无 关余氏散文的优劣, 而是集中在余氏现象对所谓文人, 文化界的冲击波上。李认为 这主要表现在真正或想像的文化精英们对余式写作及其商业成功所感到的一种塩尤 上。 ${ }^{4}$ 这种犹豫和尴尬, 在李看来, 来自余秋雨新时期 “文化战士” 的写作身份 上。 ${ }^{5}$ 这样余既是他们的同志又是异己。但是在哪种意义上余既是他自认为同道的 文人们的同志或异己呢? 首先, 似乎所有的余评, 不论是激赏或者是轻营之至的, 都认定并认同余对 “文化” 的热爱。余在写作中习惯地使用诸如 “雄伟”、“壮 观”之类约定俗成的字眼来浓墨重彩地描述并向他最长于咏叹的 “文明” 主题致 意。他的散文或是选取中国文化史上最精彩的篇章加以大肆渲染, 或是对大家耳熟 能详的 “文化英雄” 一唱三叹; 或者是选出几个广大无知群讯的代表, 如守望莫高 窟的农民出身的王道士 ${ }^{6}$ 大加鞭鞑, 同时再把作为叙述者的自己重塑成不断探索的 行路人, 游吟作家和读者的良师。尤为重要的是, 作为他所浪迹的国族家园一一当 代人的精神废墟一一的幸运又及为不幸的历史继承者。在一些对他不无倾慕却又倍 感㨫尥的批评家眼中, 余秋雨大张旗鼓所渲染的也正是他们私下想表现的, 不过余 氏的做法似乎为他们所不屑。李书否认为余秋雨试图赤手空拳地进行一场物质主义 泛滥时代的启蒙革命。” 但是正是在此 “真正的文化人” 与余有了歧见。余氏高调 的文化英雄主义在他们看来太过赤裸做作。他的游记类散文更象充满激情的示威而 无传统随笔的半点影子。总之, 余秋雨和他的文化散文所缺乏的似乎正是他所要捍 卫的文化修养, 或者如李评所显示的那样, 余氏让人不无倾慕的文化英雄情结及情 趣过于夸张, 以至有伦俗之嫌。

但是几乎没有对余氏散文形式或内容的批评涉及到它们与当今 “商业时代” 的真正 关系, 即虽然它们也可算作某种文化先锋主义, 却并非对时代及文化商业化的对 抗。余的写作活动, 他在其文中对 “文人” 精神的大量沿用, 并非为了在一个文化 荒芜的时代重建文化之尊的风车之战, 虽然从余氏文章不断重复、一唱三叹的内容 来看很像如此。

作为一种文化现象, 余氏 “文化大散文” 及其前所未有的商业成功, 以及由此带来 的散文文类的奇迹般的复苏, 实际上是中国当代文人在改革后时代舞台上最初失落 后重新胜利登台的例证之一。余极具原创性地运用了他作为社会主义时期颇为成功 的中国学院知识分子的知识结构和文化资本, 包括其几十年来对国族文化的规定想 象和运作。他充满想象力地搜寻出中外文明史中的英雄业绩或令人心仪心碎的闲情 逸事, 文化或文人的悲喜闹剧, 然后颇具创造性地把它们重新改写为 “高质量” 的 新兴中国后社会主义时期中产阶级的休闲读物。余的文化先锋主义在此意义上在他

\footnotetext{
4 李书否: “余秋雨评点”, 《秋风秋雨愁繁人》, 萧夏林等主编, 北京: 文联出版社, 2000 年 版，第 79-88 页。

5 李书否: “余秋雨评点”, 《秋风秋雨愁慜人》, 萧夏林等主编, 北京: 文联出版社, 2000 年 版，第 79 页。

6 余秋雨: “道士塔”, 《文化苦旅》，上海：东方出版中心，2005 年，第 1-9页。

7 李书否: “余秋雨评点”, 《秋风秋雨愁鞄人》, 萧夏林等主编, 北京: 文联出版社, 2000 年 版，第 80 页。
}

PORTAL Vol. 4, No.1, January 2007 
为 “文化” 在当今世界上极关紧要的重新定位, 也在他为自己打造的中国新中产情 趣结构的构建人和领头人身份上。

余秋雨 “文化大散文” 现象的原创性由此并不体现在他的散文写作而是体现在他对 “文化” 的挪移上。在一次为 《美文》杂志周年庆所作的访谈中, 余解释说他并不 认为他自己的文章是严格意义上的随笔或 “大散文” ，而是抒情性的文化感谓。 因此那些认为他过份戏剧化地, 过份感伤地改变了一种原本为 “无为” “超越” 和 “闲适” 的文人文类的批评, 虽然不无准确却是无的放矢。实际上, 正是因为余毫 无掩饰, 极富创造性地对这类常被认为 “通俗” 、“煽情” 的大众文化叙述抒情手 段的运用, 才造成了他文化挪移改写工程的成功。“我的生活经历, 学术研究, 包 括近些年来的游历, 决定了我只能写出现在面世的这些东西。在写作这样的所谓的 “散文' 之前, 我没读过任何散文理论, 我写那些文章, 不能说完全没有考虑文体 的问题, 但更主要的是想倾吐一种文化感受, 那种使我坐立不安, 焦灼的感受…… 我想探测一下一个当代文化人能银入世俗社会的程度, 探测一场六长的对话到底能 召唤来多少对话者和听众”。 ${ }^{9}$ 余的自白非常准确地说明他成功的要旨, 也点明了 他的文化大散文作为一种后社会主义文化市场商业化实验工程及其成功例证的意 义。

\section{2. 新兴中产话语与国族精神家园}

余的成功及 “文化大散文” 的时兴是一场原创性的文化转换移植工程, 即把狭义上 的 “文化” 从学院课本和图书馆中, 把原来远离凡夫俗子的历史文化资料从 “文明 的废墟” 中解救出来，变为娱人却并非毫无启发性的休闲读物：游记，逸闻野史， 个人传记和地方记忆。这样, 尤为紧要地, 他同时制造出自己的文类及情趣的读者 群一满足并引导那一大批新近相对富裕的, 有相对较高教育程度的新 “中产” 成员 和向往者的精神文化饥渴, 提高他们的文化 “素质” 和 “品位”。通过对此类需求 的创造, 辨认及满足, 余把自己变成此类新兴阶级文化的先锋。他使 “文化” 和

“阶级” 同时重新定位为 “中层”一具有差异性却与人慰籍; 既与远久传统相连却 励人现世成功; 着重素质修为及怡情养性。总的说来，通过一唱三叹、浓笔重彩的 “苦旅”，余的文化被重塑为最适宜于喜好阅读与旅游的中国新中产及想往者的社 会文化符号。

谢有顺在论及由余秋雨而起的大文化散文热潮时谈到它与作为一种总体意愿的个人 创造性在当代散文变革中的解放的关系。在他看来，余式大文化散文的出现和时 行, “就是典型的个人面对自然, 历史时的一次成功的突入和创造。在他身后, 游

8 白重暄： “做二十一世纪中华文化建设的有心人一一古城西安访余秋雨” , 《秋风秋雨愁繁 人》，萧夏林等主编， 2000 年，325页。

9 白重暄: “做二十一世纪中华文化建设的有心人一一古城西安访余秋雨” , 《秋风秋雨愁繁 人》，萧夏林等主编，2000 年，第 325 页。

PORTAL Vol. 4, No.1, January 2007 
记有了更深的人文追索的意味, 历史也在个人视角下进行了现代阐释和精神重 组。” ${ }^{10}$ 谢也提到余的原创性的散文改革其意在散文之外： “按照余秋雨自己的 表述, 他在自然和历史中旅行, 目的不是为了观赏和研究, 而是有一个更大的雄 心， “为社会和历史提供一些约定俗成的起码前提' ( 《文明的碎片-题叙》) , 而核心的依据是 ‘基于文化良知的健全人格' ( 《风雨天一阁》) ”。 ${ }^{11}$ 余自己 也曾十分直接, 十分形象地在一篇散文中写到: “我们这次旅行, 就是为了寻找景 物背后这种没有凝聚成实体的精神。这也是我以前在国内旅行时的目标。整整十五 年, 边走边伸手探摸, 常常大喜过望, 因为我触摸到了远处传来的体温。正像黑格 尔所说的那样，在灰烬堆中摸到了历史远去的余温”。 ${ }^{12}$ 在 “中华大地” 东西南 北 (此类 “苦旅” 及 “心旅” 后来也遍及整个世界) 可触可摸的景物中寻找历史的 余温——种可供重新想像改写的文化精神就是由余秋雨而起的文化大散文作为 “表意散文” ${ }^{13}$ 所要表的意。谢把此类散文称作表意散文是很准确的。这不仅在 于它把 “这种重新书写自然和历史的文化散文” 与过去常见的 “表物”、“表 人”、“表情” 文章相区别, 而且凸显出余的成功在于 “作者精神势力” 的表达, 而并非人们常常争论的他的散文文体有无创新或是文中的知识结构有无 “硬伤” 等。“表意的意思是, 一切的人, 事, 物, 都不是作者的表达目的, 它们都为作者 所用, 或者说都是为了伸张作者那个人化的文化感悟（“意” )”。 ${ }^{14}$ 这表现在 文中 “自然的人文化” 和 “历史的当代化” 。 ${ }^{15}$ 也可以说余有创意地写出的是人 文山水。谢认为余的散文是成功的, 虽然由他而起的大量文化散文仅仅是流俗的仿 制品。由谢看来余的成功在于他掌握了 “写作的幻术” （谢引译自弗吉利亚沃尔 夫）能把 “学问融化起来”, “能把你带到一种文化的迷幺境界, 改写你心中那些 陈旧而顽固的文化结论” 。1 ${ }^{16}$ 谢有顺进一步把 “写作的幻术” 定义为 “一种能将 景观、知识和个人创造性的 “意” 完美结合的话语能力”。 ${ }^{17}$ 而余氏散文的成功 是由于他用此话语能力为八十年代知识分子的文化关怀和文学传播找到了一条更大 众化的途径, 而他与他以后泛滥的大文化散文的作者们的区别也在于此话语能力的 有无。

谢对余氏及文化散文现象的阐释不无道理。但是他的理解的矛盾处在于他把余氏话 语能力一一其个人创造性, 与此类话语本身一一种约定俗成的知识分子的人文关 怀与 “大众”对后社会主义时期精神家园的失落与向往的迷幻组合，区分开来。

\footnotetext{
10 谢有顺: “散文之意” , 《美文欣赏》, 贾平凹主编, 北京: 人民日报出版社, 2005 年, 第 218 页。

11 谢有顺: “散文之意” , 《美文欣赏》, 贾平凹主编, 北京: 人民日报出版社, 2005 年, 第 218-219页。

12 余秋雨: 《河畔青草》, 引自谢第 219 页。

13 谢有顺: “散文之意”, 《美文欣赏》, 贾平凹主编, 北京: 人民日报出版社, 2005 年, 第 220 页。

14 同上。

15 同上。

16 谢有顺: “散文之意” , 《美文欣赏》, 贾平凹主编, 北京：人民日报出版社，2005 年，第 221 页。

17 同上。
}

PORTAL Vol. 4, No.1, January 2007 
虽然余氏散文写作及发行的成功在很大程度上归功于作者极具原创性的话语幻化能 力, 但此类话语本身及其社会文化语境是公共性的, 是一种新的 “时代” 、“社 会” 话语。这也是为什么谢无法很好地解释 “何以余秋雨的话语方式具有如此巨大 的再生性和复制性”。 ${ }^{18}$ 这种话语方式的巨大再生性和复制性一方面展示了它作 为一种成功的商业话语的典型性, 一方面凸显了它的内容、情感、表现形式及语境 的公共性。 ${ }^{19}$ 余秋雨 “个人式” 文化感叹的约定俗成性及其历史性, 一方面是八 十年代改革初期中国大陆知识分子集体文化关怀及追问的商业化继续, 一方面也是 同样受过几十年社会主义式国族宣传教育, 有着同样集体记忆的当代中国 “大众” 及其后社会主义传人，包括众多因各种各样的现代中国国族史的原因 “去国” 的 “华人” 和后代的公共文化失落情结有意无意的展现。这种话语情感的公共性也是 余氏散文 “雅俗共赏” 的真正原因。

余秋雨的 “文化苦旅” 以及由此开始的声势浩大的 “大文化” 旅行（散文）, 在此 意义上实际是一种后社会主义时期新商业化文类对一种似曾相识的公共话语的原创 性改写。它与某种约定俗成的精英文化情结和大众集体情感同时相呼应。这种似曾 相识的公共话语及情感模式其实就是现代中国文人的忧国忧民意识、启蒙向往、社 会主义时期的爱国主义教育和对国族文化英雄视时势而不断重新评判的混合, 同时 也包括了无数次重创式的 “革命” 和 “改革” 给不仅是文人而且也是现当代中国各 阶层 “大众” 带来的历史文化精神的迷惘感和失落感。在此意义上, 余秋雨作为文 化散文的始作俑者和最成功的实践者, 可能具有比其他人更多的 “才气” 和 “学 识” ${ }^{20}$ ，他的散文形式确实极具原创性一他将 “通俗” 文类的叙事手法, 戏剧性冲 突、感伤的情感结构、传奇等用于原本 “平淡”、“无故事” 的散文文体中, 并极 自然平易地融入作者当代性的人文阐释和文人情感 (当然这只指作者的早期散文创 作, 其后期作品只能被称作毫无掩饰的商业重复）。但这种所谓的个人创造性并不 与其话语情感本身的公共性相冲突。余秋雨在历史景物前的文化感叹是种与杨牧式 的受特定社会主义时期审美规定在自然与人工景物前的感叹类似的公共文化精神感 叹。其成功的 “通俗性” , 即文人和非文人的一般读者的认同, 在于此感叹的语境 的公共性及后社会主义时期 “中国人” 集体记忆，包括其情感认同形式的顽固性。

这也是为什么读者虽然常常被余在叙事层面上给人惊喜的 “传奇性” 景物、人物描 写和历史掌故叙述所吸引, 却往往觉得作者的情感结构和咏叹主题似曾相识。正是 这种 “新奇” 与 “熟悉” 互为补偿的幻术使余氏散文实为视角单一的文人山水能引 起众多非文人读者的共鸣。也可以说虽然此类文化散文所表的 “意” 为重新书写自

18 谢有顺: “散文之意” , 《美文欣赏》, 贾平凹主编, 北京: 人民日报出版社, 2005 年, 第 219 页。

19 余式文化散文的时代性公共语境之一即为郭英杰在他《当代中国的文化民族主义》一书中提到的 文化民族主义, 一种复杂的后社会主义文化现象, 致力于加强对一种新的国族文化的想象性建造。 见郭英杰, 《当代中国文化民族主义: 改革时期对民族身份认同的追寻》, 伦敦: 罗特里基出版 社, 2004 年, 第 5 页。

20 谢有顺: “散文之意” , 《美文欣赏》, 贾平凹主编, 北京: 人民日报出版社, 2005 年, 第 219 页。

PORTAL Vol. 4, No.1, January 2007 
然和历史, 但余式的重写, 对文人们和其他读者们来说, 实为另辟蹊径的安慰而非 观念情感的挑战。这也是为什么它们既得学人热评又受中产读者热捧。

以余的早期散文 “一个王朝的背影” 为例。从题目的设立和文本叙述层面所表的意 来看, 余的写作目的确实是为了 “在散文深处” 建立一种 “在人类视野里, 却经由 个人的方式进行的文化心理追索, 以及力图重建一种文化人格的努力”。 ${ }^{21}$ 因为 着眼于一个王朝的 “背影” 不仅宣告对历史的重审, 而且表明其不同的着眼点, 甚 至暗示将诉诸 “在野的文明, 异质的文化, 民间的传统” ${ }^{22}$ 之类非正统史籍及视 野。文章的开篇也确实如此:

“我们这些人，对清代总有一种复杂的情感阻隔。记得很小的时候，历史 老师讲到 ‘扬州十日” ‘嘉定十屠’ 时, 眼含泪花, 这是清代的开始; 而 讲到 ‘火烧圆明园”、“戊戌变法” 时又有泪花了, 这是清代的尾声。年 迈的老师一哭, 孩子们也跟着哭。清代历史是小学中唯一用眼泪浸润的课 程。从小种下的怨恨, 很难化解得开。老人的泪和孩子们的泪拌和在一 起，使这种历史情绪有了一种最世俗的力量。我小学的同学全是汉族, 没 有满族，因此很容易在课堂里获得一种共同语言，……是，在泪光闪闪 中，我们懂得了什么是民族大义，什么是气节…...” ${ }^{23}$

余在此对他的同辈国人的 “文化心理追索” 确实是对一种 “历史文化人格” 形成模 式的盘问。他解析了世俗的历史情绪, 大众 (通过普及的初中级教育) 情感的培养 和代代相传, 以及叙述力量尤其是以感伤模式不断重复的约定俗成的故事之间的关 系。但余的翻案文章表的是另外的意。他如此浓墨重彩地重审一个王朝的背影并非 是对官方或世俗（民间）历史的颠覆改写, 甚至也不是对约定俗成的 “爱国主义” 情绪本身的质疑。他要修正的是 “情绪化的社会评判规范” 的盲目性。这是一种典 型的现代启蒙主义式和社会主义式想象中的中国为各民族大家庭式的对 “封建正统 观念” 的批判。余只是想更加 “公正” 地说: “......满族是中国的满族, 清朝历史 是中国历史的一部份; 统观全部中国古代史, 清朝的皇帝在总体上还算是比较好 的, 而其中的康熙皇帝甚至可说是中国历史上最好的皇帝之一, 他与唐太宗李世民 一样使我这个现代汉族中国人感到骄傲”。 ${ }^{24}$ 余对庸庸国人狭险史观及情感的校 正, 由此看来, 是拓宽改写一部国族英雄传奇史, 其中的 “好人” 包括不论血统远 近的曾 “建功立业” 尤其是创了 “盛世” 的皇帝、忧国忧民又忠君的文人以及创立 了 “中国的华尔街” (山西平遥) 的商界奇人, 简而言之古往今来的成功人士。而 “坏人” 则是像因其生存档次太低以至不懂得保护祖宗留下的宝贝的 “农民出身” 的王道士之类。从其对 “盛世” 及创始人的讴歌向往, 以及对 “好” 文人 “好” 商

21 谢有顺: “散文之意” , 《美文欣赏》, 贾平凹主编, 北京: 人民日报出版社, 2005 年, 第 220 页。

22 谢有顺: “散文之意” ，《美文欣赏》，贾平凹主编，北京：人民日报出版社，2005 年，第 204 页。

23 余秋雨, 2002 年, 第 4 页。

24 余秋雨, 2002 年, 第 5 页。

PORTAL Vol. 4, No.1, January 2007 
人的击节赞赏, 不难看出余的新文化英雄史的当代适时性和适宜性。以这为主题且 好坏分明, 情节情感张落有致, 好看易读的余式文人山水, 自然能成为两岸三地数 次失乐园（精神文化家园）的文人和非文人的大众们老少咸宜的新文化漫游（重寻 乐园）的导游手册, 不过这次出游是写明不适时宜者及非成功人士（或不想或不能 成功人士）不宜的。

\section{参考书目}

奔均主编: 《散文批评》，台北正中书局，1993 年版。

曹文轩: 《20 世纪末中国文学现象研究》, 北京大学出版社, 2002 年版。

陈德锦: 《中国现代乡土散文史论》, 中国社会科学出版社, 2004 年版。

冯政: 《月冷繁华》, 当代世界出版社, 2005 年版。

郭英杰: 《当代中国文化民族主义: 改革时期对民族身份认同的追寻》，伦敦：罗 特里基出版社，2004 年版。

韩少功、蒋子丹主编: 《失控与无名的文化现实》, 云南人民出版社, 2003 年 版。

贾平凹、南帆主编: 《美文典藏: 时尚》, 海峡文艺出版社, 2002 年版。

洁尘等: 《新流言体: 八人行》, 中国华侨出版社, 2002 年版。

南帆: 《吒访感觉》, 东方出版社, 2004 年版。

余树森: 《中国现当代散文研究》, 北京大学出版社, 1993 年版。

吴炫: 《中国当代文化批判》, 学林出版社, 2004 年版。

萧夏林主编: 《秋风秋雨愁繁人》, 文联出版社, 2000 年版。

谢有顺: “散文之散, ” 《美文欣赏》, 贾平凹主编, 人民日报出版社, 2005 年 版，第 58-65 页。

余秋雨: 《山居笔记》, 文汇出版社, 2004 年版。

余秋雨: 《文化苦旅》, 东方出版社, 2005 年版。

赵海彦: 《中国现代趣味主义文学思潮》, 中国社会科学出版社, 2005 年版。 周作人: “近代散文钞: 序”, 《周作人文选》第二卷, 广州出版社, 1995 年 版。

本文作者郑怡博士现为悉尼科技大学国际研究学院研究员。此文章系与史蝶飞教授 合作，是由澳洲国家研究基金会资助的文化研究项目《论中国当代城市中产阶级审 美趣味的形成》的一部份。 